\title{
Functional Outcomes Following Posterior Cruciate Ligament and Posterolateral Corner Reconstructions. A Three-year Experience in Seremban, Malaysia
}

\author{
Ng JW', MBBS, Ahmad AR2, MMed Orth, Solayar GN², FRCSI \\ 'Department of Orthopaedics, International Medical University, Kuala Lumpur, Malaysia \\ ${ }^{2}$ Department of Orthopaedics, Hospital Tuanku Ja'afar, Seremban, Malaysia \\ ${ }^{3}$ Department of Orthopaedics, International Medical University, Seremban, Malaysia \\ This is an open-access article distributed under the terms of the Creative Commons Attribution License, which permits unrestricted use \\ distribution, and reproduction in any medium, provided the original work is properly cited \\ Date of submission: 15 th July 2019 \\ Date of acceptance: 19th April 2020
}

\begin{abstract}
Introduction: This study was conducted to evaluate the demographics, causes and outcomes of patients who underwent Posterior Cruciate Ligament (PCL) reconstruction and/or Posterolateral Corner (PLC) reconstruction performed at our institution over the last three years. Sub-analysis was performed to assess the impact of delay from injury to surgery and how this affected outcomes. Materials and Methods: From an initial number of 10 patients, seven were contactable and available for analysis. All patients underwent PCL and/or PLC reconstruction (modified Larson's procedure) between 2017 and 2019. The mean age of our cohort was $31.4 \pm 9.6$ years (range, 21 to 46 ). Assessment of functional outcomes pre- and postoperatively were done using the Lysholm knee scoring scale, the Knee injury and Osteoarthritis Outcome Score (KOOS) and visual analogue scale (VAS). The mean follow-up from operation at time of reporting was seven months (range, 2 to 12 months).

Results: There were four combined PCL and PLCs, two isolated PLCs and one patient who underwent an isolated PCL reconstruction. There were significant improvements between pre-operative and post-operative in all functional outcome scores utilised following PCL reconstruction and/or modified Larson's reconstruction. Lysholm knee scoring scale improved from pre-operative to post-operative at $41.14 \pm 12.32$ to $74.86 \pm 13.52(p=0.0001)$, KOOS from $49.71 \pm 11.19$ to $71.43 \pm 13.84(\mathrm{p}=0.001)$, and VAS from $5.71 \pm 2.06$ to $2.86 \pm 2.48(\mathrm{p}=0.001)$. Our sub-analysis showed that higher functional outcomes were present when surgery was done less than six months from the time of index injury. There were no complications (eg. Infections, revisions) in this cohort at the time of reporting.
\end{abstract}

Conclusion: Reconstructive surgery for PCL and/or PLC injury is successful in increasing the functional outcomes of patients post-operatively. Delays from injury to surgery remains a problem in the public setting as patients may need to await appropriate imaging and approval of funding. Increased awareness for early surgical intervention may improve overall outcomes of PCL and/or PLC reconstruction in Malaysia.

\section{Keywords:}

posterior cruciate ligament (PCL) injury, posterolateral corner (PLC) injury, PCL reconstruction, modified larson's reconstruction, functional outcomes

\section{INTRODUCTION}

The posterior cruciate ligament (PCL) is one of the strongest ligaments found in the knee, and it acts as a primary stabiliser for the posterior part of the joint ${ }^{1}$. It works closely with the structures of the posterolateral corner (PLC) to prevent posterior translation of the tibia and rotational instability. Structures that constitute the PLC are the fibular collateral ligament, popliteofibular ligament, popliteus tendon, arcuate ligament and extracapsular iliotibial band. Injuries of the PCL are normally associated with a concomitant PLC injury however, these are uncommon when compared to anterior cruciate ligament injuries ${ }^{2}$. If these (PCL and PLC) injuries are not managed appropriately, they may lead to chronic knee instability and functional disability. Partial PCL tears associated with a low grade PLC injury may be managed by non-operative treatment such as physical therapy with acceptable results in most cases. On the other hand, reconstructive surgery would be indicated 
when there is a complete PCL tear and a high grade PLC injury ${ }^{1}$.

This study retrospectively evaluated the outcomes of patients who underwent arthroscopic PCL reconstruction and/or modified Larson's PLC reconstruction at our institution being the state referral centre for Negeri Sembilan. We hypothesised that shorter time between injury to surgery would result in improved early functional outcomes compared to delayed reconstruction.

\section{MATERIALS AND METHODS}

A total of 10 patients with isolated PCL tear, isolated PLC or combined injury who underwent PCL reconstruction and/or modified Larson's reconstruction between 2017 and 2019 in Hospital Tuanku Ja'afar, in Seremban were identified. Of these, seven patients were retrospectively analysed (the rest were uncontactable). Inclusion criteria were patients aged more than 18 years old, presented with knee pain or instability, examination findings of positive posterior drawer test, positive posterior sag, positive varus stress test and magnetic resonance imaging (MRI) findings consistent with PCL tear. Exclusion criteria were revision or bilateral PCL reconstruction, combined ACL and PCL tear, PCL avulsion fracture, medial collateral ligament injury and knee osteoarthritis prior to surgery. Acute ligament injury was defined as a tear that occurred within three weeks prior to surgery; the rest were deemed as chronic injuries. Prior to surgery, options of non-operative and operative managements were discussed with all patients. All surgical procedures were carried out by a single, fellowship trained surgeon (G.N.S.).

The patient was placed in a supine position and under general anaesthesia. Prior to surgery, the affected knee was examined to assess degree of posterior and rotational instability. High tourniquet was used during the procedure. Knee arthroscopy was performed to identify the PCL disruption. PCL reconstruction was performed first in cases where a combined procedure was performed. All PCL reconstruction cases were performed using allograft (Achilles tendon) via an all arthroscopic single bundle reconstruction technique (reconstructing the anterolateral bundle). Following, PCL reconstruction, reconstruction of the PLC using modified Larson's technique was initiated. The graft used for PLC reconstruction was either allograft (if combined procedure was performed) or by harvesting patient's ipsilateral semitendinosus tendon as autologous graft (if PLC performed as sole procedure) $)^{3,4}$.

Post-operatively, all patients were kept in a brace locked in extension and given modalities to reduce swelling. They were regularly followed up by both orthopaedic surgeon and sports physicians at the institution and a PCL specific brace was employed by week 2 post-operation.

Outcome evaluations were done through functional assessment. The functional assessment consisted of the Lysholm knee scoring scale, visual analogue scale (VAS) and the Knee injury and Osteoarthritis Outcome Score (KOOS) with subscales of Pain, Symptoms, Activities of Daily Living (ADL) and Quality of Life (QOL). All the assessments were done retrospectively for pre-operative and at post-operative scores in all patients.

The statistical analysis was performed by using SPSS software [ver. 25.0; Chicago, Illinois, USA]. Comparisons in between pre-operative and post-operative functional assessment scores were performed using the paired Student $t$ test. Continuous variables were reported as mean values followed by standard deviation. P values of less than 0.05 were considered to be statistically significant.

\section{RESULTS}

The mean age of the seven patients was 31.4 \pm 9.6 years, ranging from 21 to 46 years. Four patients were in between 21 to 30 years old, one was in between 31 to 40 years old and the remaining two were above 40 years old. Six of the patients $(86 \%)$ were male and all patients were Malay. Motor-vehicle accidents were the most common injury mechanisms which accounted for six patients while one patient suffered from workplace injury.

Four patients had combined PCL and PLC injuries, two had isolated PLC injuries and the remaining one patient had an isolated PCL tear. Four patients sustained injuries on the left knee and the other three were on the right knee. The mean duration from injury to surgery was $10.4 \pm 4.4$ months, ranging from 5 to 17 months. Only one patient had reconstruction surgery done in within six months of injury. No surgical complications (eg. Infection, revision, failure of graft) were reported in this cohort.

Pre-operatively, the mean Lysholm knee scoring scale was $41.14 \pm 12.32$. The lowest Lysholm knee scoring scale was $21 \%$ and the highest was $57 \%$ pre-operatively. There were significant improvements post-operatively with a mean score of $74.86 \pm 13.52(p=0.0001)$. Post-operatively, the highest score was $92 \%$ and the lowest was $57 \%$. KOOS also increased significantly from $49.71 \pm 11.19$ pre-operative to $71.43 \pm 13.84$ post-operatively $(\mathrm{p}=0.001)$. KOOS ranged from $32 \%-63 \%$ at pre-operative to $54 \%-92 \%$ at post-operative. The mean VAS pre-operatively was $5.71 \pm 2.06$ (range, 3 to 8). This improved significantly to a mean score of $2.86 \pm 2.48$ (range, 0 to 6$)$ post-operative $(\mathrm{p}=0.001)$ (Table I). 
Table I: Summary of patients' demographic characteristics cause of injury, delay to surgery and functional outcomes

\begin{tabular}{|c|c|c|c|c|c|c|c|c|c|}
\hline \multirow[t]{2}{*}{ Patient } & \multirow[t]{2}{*}{ Operation } & \multirow{2}{*}{$\begin{array}{l}\text { Mechanism } \\
\text { of Injury }\end{array}$} & \multirow{2}{*}{$\begin{array}{l}\text { Delay to } \\
\text { Surgery }\end{array}$} & \multicolumn{2}{|c|}{ Lysholm } & \multicolumn{2}{|c|}{ KOOS } & \multicolumn{2}{|c|}{ VAS } \\
\hline & & & & Pre & Post & Pre & Post & Pre & Post \\
\hline 1 & $\mathrm{PCL}$ & MVA & 17 months & 40 & 75 & 57 & 81 & 3 & 0 \\
\hline 2 & PLC & MVA & 7 months & 21 & 58 & 32 & 57 & 8 & 4 \\
\hline 3 & PLC & MVA & 8 months & 57 & 92 & 63 & 92 & 5 & 0 \\
\hline 4 & $\mathrm{PCL}+\mathrm{PLC}$ & MVA & 9 months & 44 & 74 & 46 & 68 & 3 & 1 \\
\hline 5 & $\mathrm{PCL}+\mathrm{PLC}$ & MVA & 5 months & 42 & 88 & 47 & 81 & 7 & 5 \\
\hline 6 & $\mathrm{PCL}+\mathrm{PLC}$ & Occupational accident & 10 months & 31 & 57 & 42 & 54 & 7 & 6 \\
\hline 7 & $\mathrm{PCL}+\mathrm{PLC}$ & MVA & 17 months & 53 & 80 & 61 & 67 & 7 & 4 \\
\hline
\end{tabular}

\section{DISCUSSION}

Sixty percent of PCL injuries are complicated by a concomitant PLC injurys. Persistent knee instability and chronic pain are the main reasons for the patient to undergo reconstructive surgery. Our study aims to evaluate the outcomes of patients undergoing arthroscopic single bundle posterior cruciate ligament reconstruction and/or posterolateral corner reconstruction and to determine whether time interval between injury and surgery affects the results at this single institution.

Motor vehicle accidents and sports are two well-known causes of PCL injury. In Malaysia, Che Ahmad et $a l^{6}$ revealed that $67 \%$ of the patients with PCL tear sustained motor vehicle accidents. According to Caldas et $a l$ and Schulz et $a l^{8}$ motor vehicle accidents were the leading factor for isolated and combined PCL injuries which accounted for $78.8 \%$ and $45 \%$ of their cohort. On the other hand, Bernhardson et $a l^{9}$ suggested that $78 \%$ of the patients suffered the PCL injury as a results of trauma due to sports event. In our study, motor vehicle accident was the main cause of injuries in the majority of our patients ( 6 out 7 ).

Many studies have shown that PCL reconstruction with or without a modified Larson's gives rise to significant improvements in terms of functional outcomes ${ }^{2,10-12}$. A systematic review from 2000 to 2016 by Petrillo et $a l^{5}$ revealed that PCL and PLC reconstruction had led to an increase in the Lysholm score from $54.7 \pm 9.1$ to $83.2 \pm 4.9$ in 66 patients. Kim et $a l^{13}$ evaluated outcomes of combined PCL and PLC reconstructions in 42 patients and showed better results in Lysholm functional scores during final follow-up at two to six years when compared to preoperation. Another study done by Kim et $a l^{14}$ showed Lysholm scores also rose remarkably from pre-operative $59.63 \pm 4.49$ to post-operative $83.04 \pm 5.68$ in combined reconstruction. Mygind-Klavsen et $a l^{2}$ and Lind et $a l^{15}$ also reported that there were significant improvements in KOOS from pre-operative to final follow-up. From our study, both Lysholm knee scoring scale and KOOS showed significant improved differences pre- and post-operatively; with similar results as shown by other authors internationally.
The optimal time from injury to surgery remains one of the controversial issues in the outcomes of patients as mentioned earlier $^{16-18}$. Early interventions may allow earlier rehabilitation and mobility of the knee joint and thus, has the potential of improving overall success rates following reconstruction. However, higher risks of arthrofibrosis has been reported in early reconstruction cases and this may be a reason to opt for delayed reconstruction ${ }^{16}$. Hohmann et $a l^{17}$ have reported that early surgical reconstruction for injuries of knee ligaments had markedly better outcomes in term of Lysholm scores than late surgical intervention. Conversely, Rusdi et $a l^{18}$ reviewed that there was no association between the optimal time of surgery and patients' Lysholm scores. Our study suggested that higher functional outcomes were present when the reconstructive surgery was done less than six months from injury. A longer duration of more than six months from injury to surgery in most of the patients were due to delays in obtaining appropriate imaging and funding approval for surgical intervention.

This study has several limitations. The small number of patients makes it difficult to make strong conclusions on the effect of delayed surgery however, our results do favour earlier intervention. We acknowledge that heterogenicity of aetiologies (PCL, PLC and combined) may foreshadow direct comparison however, as there is a paucity in the Malaysian body of literature at present with regards to outcomes of these injuries, we opted to include them in this review.

\section{CONCLUSION}

Reconstructive surgery for PCL and/or PLC injury is successful in increasing the functional outcomes of patients post-operatively. Delays from injury to surgery remains a problem in the public setting as patients may need to await appropriate imaging and approval of funding. Increased awareness for early surgical intervention may improve overall outcomes of PCL and/or PLC reconstruction in Malaysia.

\section{CONFLICT OF INTEREST}

The authors declare no conflicts of interest. 


\section{REFERENCES}

1. Pache S, Aman ZS, Kennedy M, Nakama GY, Moatshe G, Ziegler C, et al. Posterior cruciate ligament: current concepts review. Arch Bone Jt Surg. 2018; 6(1): 8-18.

2. Mygind-Klavsen B, Nielsen TG, Lind MC. Outcomes after posterior cruciate ligament (PCL) reconstruction in patients with isolated and combined PCL tears. Orthop J Sports Med. 2017; 5(4): 2325967117700077. doi: 10.1177/2325967117700077

3. Niki Y, Matsumoto H, Otani T, Enomoto H, Toyama Y, Suda Y. A modified Larson's method of posterolateral corner reconstruction of the knee reproducing the physiological tensioning pattern of the lateral collateral and popliteofibular ligaments. Sports Med Arthrosc Rehabil Ther Technol. 2012; 4(1): 21. doi: 10.1186/1758-2555-4-21

4. Zantop T, Peterson W. Modified Larson Technique for Posterolateral Corner Reconstruction of the Knee. Oper Orthop Traumatol. 2010; 22(4): 373-86. doi: 10.1007/s00064-010-9030-9

5. Petrillo S, Volpi P, Papalia R, Maffulli N, Denaro V. Management of combined injuries of the posterior cruciate ligament and posterolateral corner of the knee: a systematic review. Br Med Bull. 2017;123(1): 47-57. doi: 10.1093/bmb/ldx014

6. Che-Ahmad A, Najmi NMF, Samsudin OC, Yeap JK, Hyzan MY. Surgical reconstruction in chronic posterior cruciate ligament injuries of the knee. IMJM. 2015; 14(2): 29-34.

7. Caldas MTL, Braga GF, Mendes SL, Silveira JM, Kopke RM. Posterior cruciate ligament injury: characteristics and associations of most frequent injuries. Rev Bras Ortop. 2013; 48(5): 427-31. doi: 10.1016/j.rboe.2012.09.010

8. Schulz MS, Russe K, Weiler A, Eichhorn HJ, Strobel MJ. Epidemiology of posterior cruciate ligament injuries. Arch Orthop Trauma Surg. 2003; 123(4): 186-91. doi: 10.1007/s00402-002-0471-y

9. Bernhardson AS, DePhillipo NN, Daney BT, Kennedy MI, Aman ZS, LaPrade RF. Posterior tibial slope and risk of posterior cruciate ligament injury. Am J Sports Med. 2019; 47(2): 312-7. doi: 10.1177/0363546518819176

10. Shon OJ, Park JW, Kim BJ. Current Concepts of Posterolateral Corner Injuries of the Knee. Knee Surg Relat Res. 2017; 29(4): 256-68. doi: 10.5792/ksrr.16.029

11. Cury RPL, Castro Filho RN, Sadatsune DA, Prado DR, Goncalves RJP, Mestriner MB. Double-bundle PCL reconstruction using autologous hamstring tendons: outcome with a minimum 2-year follow-up. Rev Bras Ortop. 2017; 52(2): 203-9. doi: 10.1016/j.rboe.2017.02.006.

12. Hermans S, Corten K, Bellemans J. Long-term results of isolated anterolateral bundle reconstructions of the posterior cruciate ligament: a 6- to 12-year follow-up study. Am J Sports Med. 2009; 37(8): 1499-507. doi: 10.1177/0363546509333479

13. Kim SJ, Jung M, Moon HK, Kim SG, Chun YM. Anterolateral transtibial posterior cruciate ligament reconstruction combined with anatomical reconstruction of posterolateral corner insufficiency: comparison of single-bundle versus double-bundle posterior cruciate ligament reconstruction over a 2- to 6-year follow-up. Am J Sports Med. 2011; 39(3): 481-9. doi: $10.1177 / 0363546510385398$

14. Kim SJ, Lee SK, Kim SH, Kim SH, Jung M. Clinical outcomes for reconstruction of the posterolateral corner and posterior cruciate ligament in injuries with mild grade 2 or less posterior translation: comparison with isolated posterolateral corner reconstruction. Am J Sports Med. 2013; 41(7): 1613-20. doi: 10.1177/0363546513485927

15. Lind M, Nielsen TG, Behrndtz K. Both isolated and multi-ligament posterior cruciate ligament reconstruction results in improved subjective outcome: results from the Danish Knee Ligament Reconstruction Registry. Knee Surg Sports Traumatol Arthrosc. 2018; 26(4): 1190-6. doi: 10.1007/s00167-017-4577-8

16. Mabvuure NT, Malahias M, Haddad B, Hindocha S, Khan WS. State of the art regarding the management of multiligamentous injuries of the knee. Open Orthop J. 2014; 8: 215-8. doi: 10.2174/1874325001408010215

17. Hohmann E, Glatt V, Tetsworth K. Early or delayed reconstruction in multi-ligament knee injuries: A systematic review and metaanalysis. Knee. 2017; 24(5): 909-16. doi: 10.1016/j.knee.2017.06.011

18. Rusdi A, Shahrulazua A, Siti HT, Nizlan NM. Short-term functional outcomes of a delayed single-stage reconstruction of chronic posterior cruciate ligament and posterolateral corner deficiency. Clin Ter. 2014; 165(1): e28-34. doi: 10.7471/CT.2014.1668 